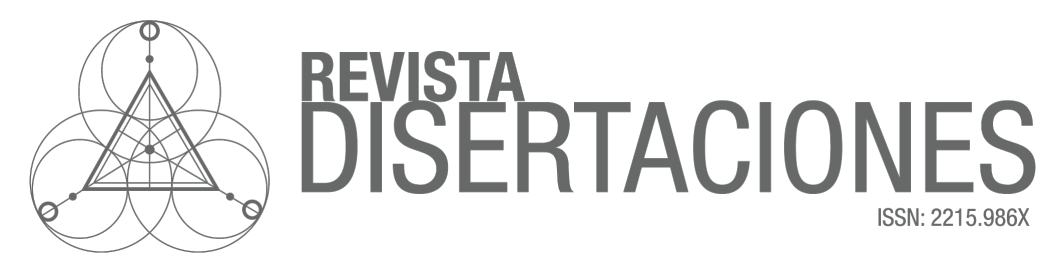

\author{
La antropofagia como descentramiento de Europa \\ Anthropophagy as Decentration of Europe \\ Erika Castañeda Sánchez \\ Universidad Nacional Abierta y a Distancia - Colombia \\ DOI: https://doi.org/10.33975/disuq.vol10n1.450
}

\title{
$\Phi$
}

\begin{abstract}
Resumen
El presente escrito hace una aproximación al trabajo literario de Oswald de Andrade desde la perspectiva benjaminiana de la historia que permite pensar un nuevo lugar para América Latina. Para alcanzar tal objetivo nos centraremos en el concepto de antropofagia a partir de dos importantes obras del autor: el "Manifiesto da poesía Pau-Brasil" (1924) y el "Manifiesto Antropófago" (1928), en las cuales de Andrade expone lo que entiende por antropofagia y cómo esta sería la característica del salvaje americano. Las afirmaciones realizadas por el escritor brasilero serán analizadas teniendo en cuenta dos aspectos del materialismo histórico propuesto por Walter Benjamin, el rechazo a la idea de progreso y la trituración del valor tradicional de la obra de arte.
\end{abstract}

Palabras clave: antropofagia, América Latina, descentramiento, orden global.

\footnotetext{
"Recibido: 15 de diciembre de 2020. Aceptado: 12 de marzo de 2021.

'Contacto: ercastan@gmail.com, erika.castaneda@unad.edu.co
} 


\begin{abstract}
This writing makes an approach to the literary work of Oswald de Andrade from the Benjaminian perspective of history which allows us to think of a new place for Latin America. To achieve this objective, we will focus on the concept of anthropophagy based on two important works by the author: the "Manifesto da Poesía Pau-Brasil" (1924) and the "Manifesto Antropófago" (1928), in which de Andrade exposes what He understands by cannibalism and how this would be the characteristic of the American savage. The statements made by the Brazilian writer will be analyzed taking into account two aspects of the historical materialism proposed by Walter Benjamin, the rejection of the idea of progress and the crushing of the traditional value of the work of art.
\end{abstract}

Keywords: Anthropophagy, Latin America, decentration, global order

Cómo citar este artículo: Castañeda Sánchez, Érika. (2021). Antropofagia como descentramiento de Europa. Revista Disertaciones, 10(1). https://doi.org/10.33975/disuq.vol10n1.450

\title{
(C) $(1) \Theta \Theta$
}

Material publicado de acuerdo con los términos de la licencia Creative Commons AttributionNonCommercial-NoDerivatives 4.0 International (CC BY-NC-ND 4.0). Usted es libre de copiar o redistribuir el material en cualquier medio o formato, siempre y cuando dé los créditos apropiadamente, no lo haga con fines comerciales y no realice obras derivadas. 


\section{La antropofagia como descentramiento de Europa}

\section{Introducción}

La tradición de los oprimidos nos enseña que la regla es el «estado de excepción» en el que vivimos. Hemos de llegar a un concepto de la historia que le corresponda. Tendremos entonces en mientes como cometido nuestro provocar el verdadero estado de excepción; con lo cual mejorará nuestra posición en la lucha contra el fascismo (...) No es en absoluto filosófico el asombro acerca de que las cosas que estamos viviendo sean «todavía» posibles

en el siglo veinte. No está al comienzo de ningún conocimiento, a no ser de éste: que la representación de historia de la que procede no se mantiene.

Walter Benjamin, Tesis de filosofía de la historia

Estas palabras de Benjamin pueden resultar iluminadoras al momento de pensar la situación de América Latina (AL), en relación con Europa y Norte América. Si bien las diferentes posturas intelectuales contemporáneas esquivan y/o critican el uso de términos como opresión, víctima, dependencia, entre otros, por considerarlos herederos de legados teóricos poco críticos, aun así, considero que estos términos crean una imagen muy cercana a la experiencia de desigualdad que puede observarse en AL. Tal como queda señalado en la "Tesis de filosofía de la historia", la condición de opresión de unos sujetos en función del bienestar de otros encuentra justificación en el ideal de progreso creado por Occidente, de ahí que una transformación en la historia de AL, no implique sólo la reformulación de la identidad de una pequeña región del mundo, sino que, ante todo, la reconstrucción de AL implica la transformación del ideal de progreso que ha servido para leer la historia (Cf. Benjamin 1971 77).

Es importante en este sentido señalar que, si bien este cambio debe implicar el abandono de la idea del atraso de AL frente a Europa y EEUU, también se hace necesario que la nueva forma de interpretar a AL no se centre en la apología de un pasado predescubrimiento que no es recuperable, pues de enfocarse el cambio en una posición 


\section{Érika Castañeda Sánchez}

semejante, se estaría negando uno de los fenómenos históricos que es condición de posibilidad de AL, su encuentro con Occidente. Por esta razón, considero que la noción Antropofagia, de Oswald de Andrade, que aparece tanto en el "Manifiesto da poesía PauBrasil" (1924) como en el "Manifiesto Antropófago" (1928), puede resultar de gran ayuda en la empresa de reconstruir el lugar de AL en la historia, pues este autor antes de pensar en una esencia prehispánica de lo latinoamericano, considera que lo propio del hombre es el canibalismo, siendo el salvaje americano, el único capaz de dar cuenta de esa característica humana.

En razón de esto, el propósito del presente escrito será realizar un breve acercamiento a la propuesta de de Andrade, con el fin de ver sus alcances en la reformulación de AL, teniendo en cuenta dos aspectos importantes de la comprensión de la historia en Walter Benjamin: su ruptura con la noción de progreso y con la autoridad de la tradición. Para lograr el propósito aquí mencionado, se realizará un acercamiento a la perspectiva que sobre la historia tiene el filósofo alemán y luego este texto se centrará en el trabajo de de Andrade, visibilizando en él los aspectos en los que su propuesta de Antropofagia se acerca a la noción de historia de Benjamin.

Benjamin y su perspectiva materialista de la historia

Para Walter Benjamin, una construcción materialista de la historia supone, necesariamente, romper con la idea de progreso, puesto que, esa conciencia impuesta de que avanzamos, no solo en el tiempo físico, sino también en el tiempo histórico legitima al vencedor. Es decir, para este autor la idea de progreso contribuye a la victimización de los vencidos. Es por ello que, para el filósofo alemán, la idea de progreso convierte la historia en "un tiempo homogéneo y vacío", en el cual los hechos se producen de forma necesaria, siempre, en favor del progreso humano.

En ese sentido, el filósofo alemán critica al positivismo histórico pues considera que, tras la promesa de narrar el pasado tal y como verdaderamente fue, esta escuela reproduce 


\section{La antropofagia como descentramiento de Europa}

una versión de la historia que solo toma en cuenta los hechos que considera importantes para el progreso del espíritu humano. Estos son aquellos acontecimientos que se identifican con el vencedor, con sus ideales y sus intereses, negando con esto un lugar en la historia para aquellos que fueron derrotados. En palabras del autor:

La imagen verdadera del pasado pasa de largo velozmente. El pasado sólo es atrapable como la imagen que refulge, para nunca más volver, en el instante en que se vuelve reconocible. "La verdad no se nos escapará": esta frase que proviene de Gottfried Keller indica el punto exacto, dentro de la imagen de la historia del historicismo, donde le atina el golpe del materialismo histórico. Porque la imagen verdadera del pasado es una imagen que amenaza con desaparecer con todo presente que no se reconozca aludido en ella (Benjamin 1971 79).

En este fragmento de la $\mathrm{V}$ tesis, Benjamin muestra esta distancia que debe haber entre el historicismo y la historia materialista, señala, por un lado, que el materialismo está llamado asestar un golpe al historicismo, abriendo un espacio en la historia para aquellos a los que el historicismo amenaza con desaparecer, es decir, a los vencidos. Esa imagen de la verdad que pasa velozmente para no ser vista nunca más, es justamente el pasado derrotado, que puede dejar de existir bajo la narración historicista. Más adelante, en la IX tesis, este pensador radicalizará su crítica al progreso, al mostrar que esta idea es la que produce la catástrofe, así, tomando como analogía de la historia un cuadro de Klee en autor afirmará:

Hay un cuadro de Klee que se titula Angelus Novus. Se ve en él un ángel, al parecer en el momento de alejarse de algo sobre lo cual clava la mirada. Tiene los ojos desorbitados, la boca abierta y las alas tendidas. El ángel de la historia debe tener ese aspecto. Su rostro está vuelto hacia el pasado. En lo que para nosotros aparece como una cadena de acontecimientos, él ve una catástrofe única, que arroja a sus pies ruina sobre ruina, amontonándolas sin cesar. El ángel quisiera detenerse, despertar a los muertos y recomponer lo destruido. Pero un huracán sopla desde el paraíso y se arremolina en sus alas, y es tan fuerte que el ángel ya no puede plegarlas. Este huracán lo arrastra irresistiblemente hacia el futuro, al cual vuelve las espaldas, mientras el cúmulo de ruinas 


\section{Érika Castañeda Sánchez}

crece ante él hasta el cielo. Este huracán es lo que nosotros llamamos progreso (Benjamin 1971 82).

En esta hermosa metáfora del ángel de la historia, el autor nos presenta nuevamente el peligro que el progreso supone para el pasado, puesto que la idea de avance histórico sepulta a todos aquellos que no se reconocen en el proyecto de los vencedores. En ese sentido, la reconstrucción de los hechos realizada por el historicismo es siempre la fuente de legitimación del vencedor y por lo mismo, la destrucción de culturas y sociedades enteras se reproducen como hechos a favor del perfeccionamiento de la humanidad. Pero no sólo saca de la narración a las víctimas del pasado, sino también a las del presente, pues para este pensador la historia teje secretas conexiones entre el pasado y el ahora. El pasado oprimido es el arma con la que se combate al vencedor en el presente, de ahí que la historia, tal como se aprecia en el fragmento citado de la tesis $\mathrm{V}$, entre el pasado de los vencidos es el arma con la cual se puede asestar el golpe al historicismo. Es por esto que la historia resulta de gran relevancia para el autor, pues para él el pasado no es sólo un recuento de los hechos acontecidos, sino un proyecto político, con el cual se busca dar un salto en el tiempo y posicionar la voz de lo que ayer fueron callados.

Otro aspecto importante de esta comprensión de la historia se encuentra en su ensayo titulado "La obra de arte en la época de su reproductibilidad técnica", en el cual compara el arte producido por un genio/artista y el arte producido por la técnica. El primero, es un arte ligado a la tradición, a un aquí y un ahora que es irrepetible, y que recoge toda la historia del objeto artístico, desde su origen asociado al nombre del genio que lo hizo posible, hasta sus alteraciones físicas o sus cambios de propietario (Cf. Benjamin 1989 3). Este arte, señala el autor, tiene aura, la cual define como una distancia que impone la obra a sus espectadores, así estos se encuentren cerca de la obra, pues dicha distancia es de naturaleza histórica y no espacial; es decir, el aura es aquello que le confiere al objeto artístico un valor de culto que mantiene alejado de quien lo observa. El arte reproducido por la técnica está desposeído de aura, no se oculta, sino que gracias a su forma de producción y reproducción puede estar en diferentes lugares y sale en busca de sus espectadores. Esa aura que garantiza la autenticidad del objeto artístico, al ser sustraída en la reproducción técnica, libera a la imagen de la tradición, no solo en las nuevas 


\section{La antropofagia como descentramiento de Europa}

imágenes que produce sino también al reproducir las imágenes de culto. Puesto que la máquina productora de imágenes puede exhibir detalles de la obra que no son perceptibles al ojo humano, quedando de esta manera desprovista por completo de misterio.

Esta liquidación del valor cultual de la imagen que se produce con la técnica, tiene para el autor importancia política, no sólo porque acerca el arte a las masas, sino porque esta masificación de la imagen expresa la percepción sensorial propia de la época de la reproducción técnica. Una percepción "cuyo sentido para lo igual en el mundo ha crecido tanto que incluso, por medio de la reproducción, le gana terreno a lo irrepetible" (Benjamin 1989 5). Así, al poner en evidencia el cambio que acontece en la percepción de las masas, se modifica también la relación de las masas frente al arte, pues de parecer escasas de conocimiento frente a un objeto aurático, pasan a ser grandes conocedoras y críticas frente al cine. Este fenómeno hace obsoleta la crítica que pretende deslegitimar la cultura de masas cuando afirma que "las masas buscan disipación, pero el arte reclama recogimiento" (Id. 17).

En esta breve reconstrucción de la teoría de la historia de Walter Benjamin podemos ver que hay dos aspectos que resultan fundamentales para la consolidación política del materialismo histórico. Por un lado, encontramos su crítica a la idea de progreso impuesta por el historicismo, en virtud de que esta construcción de la historia legitima a los verdugos y revictimiza a los vencidos. Por otro lado, la trituración del aura, que es también la aniquilación del valor cultual del objeto artístico, y con esto la ruptura con el ciego reconocimiento a la tradición. A continuación, se pasará al concepto de antropofagia de Oswald de Andrade, con el fin de ver, con ayuda del concepto de historia aquí expuesto, la potencia política del escritor suramericano. 


\section{Erika Castañeda Sánchez}

Antropofagia como negación del progreso y la autoridad

San Pablo, Brasil, lugar en el que se inicia el movimiento antropofágico, es para la década de 1920 un centro urbano que se abre a la industrialización y, con esto, a todas las manifestaciones culturales propias de las ciudades modernas, como las exposiciones de arte, los encuentros literarios, etc. Para esta época, los intelectuales brasileros han entrado en contacto con las vanguardias artísticas de Europa, como el futurismo, el cubismo, el surrealismo, entra otras. En 1922 Oswald de Andrade, quien para esta época ya ha realizado diferentes viajes a Europa, publica en San Pablo, el "Manifiesto da poesía PauBrasil". En éste libro, el autor, antes que interesarse por un nacionalismo literario esencialista, busca provocar una nueva forma de pensar lo brasilero, que no excluye lo ajeno, sino que se lo apropie sin sacralizarlo. En otras palabras, lo que busca legitimar de Andrade es una apropiación sin reconocimiento de la autoridad:

Contra el gabinetismo, la práctica culta de la vida. Ingenieros en vez de jurisconsultos, perdidos como chinos en la genealogía de las ideas.

La lengua sin arcaísmos, sin erudición. Natural y neológica. La contribución millonaria de todos los errores. Como hablamos, como somos (37).

Vemos que, por un lado, de Andrade se refiere al portugués, el idioma heredado de la colonización. Por otro lado, afirma un nuevo portugués, el portugués de Brasil. Un idioma diferente, pero construido a partir del idioma del colonizador. Este portugués no depende para su funcionamiento del seguimiento de las reglas que dictamina la gramática de Portugal. A diferencia de esto, el nuevo portugués es el resultado del desvío, del equivoco, del descuido, es "la contribución millonaria de todos los errores". Esta disposición a tomar lo que se necesita y ponerlo a funcionar en la creación de algo nuevo, puede observarse también en su preferencia por la ingeniería antes que por el derecho. La primera es vista como el conocimiento que produce, que crea, mientras que el derecho parece anclado al cuidado de la tradición, de preservar la autoridad de lo que se hereda. 


\section{La antropofagia como descentramiento de Europa}

Para comprender más este papel conservador del conocimiento, resulta pertinente lo señalado por Aníbal Quijano, quien afirma que, cuando Europa emprende su campaña colonizadora, la diferencia racial cobra el sentido que tiene en la actualidad, el cual ha servido para justificar tanto las relaciones de dominación instauradas en la época colonial, como la actual diferencia en el mercado internacional entre países desarrollados y países en vía de desarrollo (2014 205-206). La razón por la cual se mantiene la diferencia creada por los conquistadores, más allá del periodo colonial, está relacionada con dos factores. En primera instancia, la codificación de una supuesta superioridad intelectual en la diferencia racial, lo cual es obra de los intelectuales europeos del siglo XVIII y XIX.

Puede observarse para este caso, lo señalado por Santiago Castro-Gómez en "La Hibrys del Punto Cero", texto en el cual el autor afirma que, durante la época colonial (XVI-XVIII) se instaló en La Nueva Granada una organización social que tenía como criterio principal de distribución de roles sociales el factor étnico. Los españoles que durante el periodo de conquista se convirtieron en la raza blanca dominante, buscaron legitimar la superioridad de su etnia a partir de discursos provenientes de diferentes áreas del conocimiento, como la antropología y la economía. Estos discursos demostraban la superioridad de la raza blanca sobre las demás. Desde la antropología filosófica, uno de los principales autores que avalaba esta diferencia social fue Immanuel Kant. En su teoría antropológica, Kant consideraba la existencia de cuatro razas, la blanca (europea), la amarilla (asiática), la negra (africana) y la roja (americana-indígena). La diferencia entre éstas no se limitaba solo al color de su piel o a su ubicación geográfica, sino que se extendía a la capacidad para la construcción de un carácter moral. Así, desde esta perspectiva, la raza blanca era la única que había demostrado la capacidad para autodeterminarse moralmente, mientras que las demás eran moralmente inferiores y, por tanto, debían estar bajo la tutela de la raza superior (Castro-Gómez 41). Desde la perspectiva económica, el argumento que legitimaba la superioridad española estaba conectado con la posibilidad de alcanzar un desarrollo en la producción de bienes que permitiera el abastecimiento de la mayor parte de los individuos de una sociedad. Desde luego, tal modelo de producción tenía su correlato en el modelo industrial europeo. 


\section{Érika Castañeda Sánchez}

Encontramos también, que la actitud de las élites intelectuales y económicas nacidas en territorio americano ayudó a la consolidación de esta superioridad, pues los criollos nunca pusieron en duda la representación que Europa hizo de las razas. A diferencia de esto, la asimilaron y siguieron reproduciendo en las nuevas relaciones sociales instauradas con los procesos de independencia, o como en el caso de Brasil, en la transformación de reino a república.

Volviendo al trabajo del escritor brasilero, vemos que de Andrade busca alejarse de esta construcción subvalorada de América, por ello en el Manifiesto de 1924, se ha dado a la tarea de instituir una nueva forma de leer lo propio, en términos de creación, no de copia. Con esto, el autor, se aleja tanto de la construcción europea de la historia, como de la apología que hacen los criollos de lo europeo. Al tomar distancia de ese paradigma de superioridad impuesto desde la colonia y mantenido a través del tiempo, el poeta suramericano realiza la tarea política que Benjamin legaba al materialismo histórico, alejarse de la idea de progreso, pues es esta idea la que, como vemos con Castro-Gómez, está en la base de la legitimación de la travesía sangrienta que llevaron a cabo los europeos al llegar al nuevo mundo. En ese sentido, afirmar la creación de un nuevo portugués que si bien, tiene su origen en el idioma del colonizador no se doblega ante sus reglas, es una forma de asestar el golpe a la reconstrucción del descubrimiento de América consagrada en la narración historicista. Puesto que, al darle un estatus diferente al idioma del colonizado se desafía el discurso que reivindica las campañas colonizadoras y abre un lugar para aquellos que fueron subyugados en el encuentro de ambos mundos.

La poesía pau-Brasil, se abalanza contra el eurocentrismo, contra la conciencia de la superioridad del viejo continente que fue asumida por los americanos. Esto se hace evidente en fragmentos como el siguiente:

No más brasileros de nuestra época. Lo necesario de química, de mecánica, de economía, de balística. Todo digerido. Sin mitin cultural. Prácticos. Experimentales. Poetas. Sin reminiscencias librescas. Sin comparaciones de apoyo. Sin reivindicaciones etimológicas. Sin ontología. Barbaros, crédulos, pintorescos y tiernos. Lectores de diarios. Palo-delBrasil. La selva y la escuela. El Museo Nacional. La cocina, el mineral y la danza. La vegetación. Palo-del-Brasil (7). 


\section{La antropofagia como descentramiento de Europa}

Aquí, de Andrade hace énfasis en el carácter útil del conocimiento, a la vez que rechaza la solemne vestidura que le dan tanto europeos como criollos al concomimiento Occidental. Lo importante es lo que sirve, lo que puede ser digerido y transformado en algo propio. Así, la etimología, la defensa del origen, parapetos que mantienen las jerarquías intactas, son desechados, considerados irrelevantes para la nueva creación brasilera. La poesía modernista del Brasil se convierte entonces en el nuevo paradigma de lo propio, que no niega a sus ancestros, pero tampoco les da importancia. Aquí lo bárbaro es sinónimo de grandeza, pues en esta nueva construcción de lo propio, lo que resulta significativo no es en modo alguno el apellido, el abolengo, la autoridad, sino la creación de la nueva poesía, la puesta en funcionamiento de la nueva musicalidad de las palabras que sirvieron de vehículo a la experiencia de lo brasilero.

Aquí de Andrade nos acerca nuevamente al proyecto materialista de Walter Benjamin, específicamente al colapso que el arte reproducido por la técnica causa al arte aurático. En este sentido, la antropofagia no solo cuestiona la autoridad del colonizador, sino que también lo despoja de su misterio, del aura que rodea su conocimiento atiborrado de jerarquías que afirman su posición en el legado de sus antepasados. El nuevo portugués es entonces un idioma irreverente, un el lenguaje de un nuevo hombre que busca también un conocimiento nuevo, más práctico capaz de responder a los problemas y necesidades que se le presentan. Un conocimiento que no es ociosa erudición, sino práctica destructiva de la tradición.

El Brasil modernista de de Andrade, tiene como fuente de su grandeza el canibalismo, la antropofagia. La capacidad para devorar lo ajeno y crear algo nuevo. Esa misma capacidad que Benjamin identificada en la reproducción técnica de la imagen, su poder de triturar el aura. En 1928, es publicado el "Manifiesto Antropófago", en el cual el autor hace más explícita su noción de antropofagia y le da un mayor alcance que el que se observaba en el manifiesto de 1922. En este texto, de Andrade afirma que lo único "es lo ajeno", y esta es la única ley que une a todos los hombres. Así, el autor desplaza la centralidad de la razón en el pensamiento de Occidente, ya no somos animales racionales, sino simplemente animales que nos devoramos entre sí. La razón sería entonces otra forma de canibalismo. 


\section{Érika Castañeda Sánchez}

Considero, en virtud de lo anterior, que con estas palabras el autor redimensiona su noción de apropiación. Aquí lo propio de Brasil no parece ser el canibalismo, sino la conciencia que se tiene del mismo: "Sólo la Antropofagia nos une. Socialmente. Económicamente. Filosóficamente. Única ley del mundo. Expresión enmascarada de todos los individualismos, de todos los colectivismos. De todas las religiones. De todos los tratados de paz" (7). Con estas palabras queda claro que toda empresa humana pasada, presente o futura no es otra cosa que manifestación de la antropofagia. Cualquier desarrollo del espíritu humano, ya sea en la ciencia, en las artes, en la economía, en la industria, es una acción caníbal, y no el fruto del perfeccionamiento humano, como lo interpreta el historicismo.

La comprensión del canibalismo como parte de la naturaleza del hombre, se convierte así en el elemento que permite descentrar la historia construida por Europa y por lo mismo desajustar la narración positivista del pasado. Desde esta perspectiva, el resultado del intelecto occidental ya no aparece como fruto del progreso de la humanidad, sino que es visto bajo la dimensión del canibalismo, como la apropiación funcional del mundo. En otras palabras, esta novedosa apropiación que se proyecta en el texto de de Andrade implica un cambio en la construcción de la temporalidad histórica producida por Occidente, pues desde la perspectiva europea la ciencia moderna, fuente legitima del conocimiento, se encuentra revestida de un halo de autoridad. Por ello, el que acepta la ciencia, de alguna manera acepta también la superioridad de Europa. A pesar de ello, la antropofagia cambia esta situación: aquí el interés por lo ajeno no implica un reconocimiento de otra cosa que de su utilidad para afirmar lo verdaderamente humano.

En el mismo texto, más adelante, se indica que solo en América es posible la conciencia de la antropofagia. Por ello, a pesar de ser una capacidad del ser humano en general, sólo en territorio americano se potencia al máximo. Lo anterior, gracias a que solo en la ausencia de gramáticas, de patrones de uso de la lengua, solo en la ausencia de la fragmentación rígida del mundo, que se materializa en las reglas de las lenguas colonizadoras, es posible la creación. Solo bajo esta carencia es posible "una conciencia participante, una rítmica religiosa". Esta conciencia de lo nuevo que desafía la visión del atraso, es lo que hace posible ese descentramiento de Europa. 


\section{La antropofagia como descentramiento de Europa}

En virtud de lo anterior, podemos decir que el verdadero estado de excepción propuesto por Benjamin, en el epígrafe con el que inicia este texto, encuentra una posible forma de materialización en la conciencia caníbal del hombre americano. Como se puede notar en lo dicho hasta el momento, la antropofagia como parte de la nueva identidad del hombre americano no sólo modifica la posición de AL ante el mundo, sino que reconstruye la historia universal propuesta por Occidente, pues cuestiona de forma radical la narración hegemónica del encuentro entre el viejo y el nuevo continente.

Así, la antropofagia no puede ser pensada como una copia de las vanguardias europeas que se adapta a un contexto ajeno. Antes que esto, la antropofagia debe ser vista como una asimilación crítica de Europa. Es decir, si bien de Andrade no busca ocultar que su propuesta está intervenida por lo que sucede en el antiguo continente, aun así, lo que mostrará en su "Manifiesto Antropófago" es que tal intervención no se presenta en términos de asimilación pasiva de una verdad comprobada por las teorías europeas, sino que ésta es la capacidad que tiene el salvaje americano de ingerir solo lo que necesita para crear algo propio. El resto, aquello que le resulta inservible, poco relevante para sus fines, lo desecha sin ningún miramiento, sin ninguna actitud de respeto. Desde esta perspectiva, la antropofagia puede verse como una forma de desacralizar el mundo, pues el legado europeo solo puede ser importante si puede usarse. De lo contrario, todo el pasado de Europa, la historia misma de la civilización resulta irrelevante.

\section{Referencias}

Castro-Gómez, Santiago. La hybris del punto Cero. Bogotá: Editorial Pontificia Universidad Javeriana, 2005.

De Andrade, Oswald. "Manifiesto Antropófago", Revista de Antropofagia 1/1, 1928. Disponible en: http://fama2.us.es/earq/pdf/manifiesto.pdf

De Andrade, Oswald, Obra escogida. (s.f.). Disponible en: https://www.biblioteca.org.ar/libros/211587.pdf>

Benjamin, Walter. Discursos Interrumpidos I. Buenos Aires: Taurus, 1989. 


\section{Erika Castañeda Sánchez}

Benjamin, Walter. "Tesis de filosofía de la historia". En: Angelus Novus. Barcelona: Edhasa, 1971.

Quijano, Aníbal. "Colonialidad del poder, eurocentrismo en América Latina". Buenos Aires: CLACSO, 2014.2 Disponible en: http://biblioteca.clacso.edu.ar/clacso/se/20140507042402/eje3-8.pdf 